\title{
Exploring the Global Significance of Chinese Education: A New Start for Frontiers of Education in China
}

(C) Higher Education Press and Springer-Verlag 2010

In the past four years, we have carefully selected excellent articles concerning education from China's academic journals, and have translated them into English for the benefit of international readers. In these 16 issues, we have had the honor of sharing with global readers some of the most progressive developments in the theory and practice of education in China, choosing from a range of topics and diverse research methodologies. The 136 articles published so far have discussed traditional Chinese educational thought, such as Confucianism, and the ideas associated with the Academy (shuyuan) and the well-known Civil Service Examination (keju). They have also discussed modern Chinese educational practice, including efforts to close the gap in terms of equality between urban and rural education and the implementation of compulsory education; they have introduced education for minorities including the development of education in Xinjiang, and have explored research into minority teachers and students. Other articles have looked at gender equality issues in schools and reviewed the women's education movement in China, including such issues as the learning experiences of female university students. Not only has Frontiers of Education in China published research into developments in Chinese universities, such as Project 985, and the massification of higher education, but it has also looked into pre-school education and special education. We have also explored Chinese education financing, including analysis of particular funding issues, and have given a strong emphasis to research on rural and Western Chinese education. We have introduced Chinese family education and have explored the situation of moral education and nationalist education. With topics like these, we have helped guide international readers along a path of discovery of China and the Chinese education system.

Starting from 2010, our journal will undergo a fundamental change. Rather than selecting already published articles for translation, we are now soliciting original articles, written either in Chinese or English. All articles will go through peer review before being accepted for publication, and Chinese language 
submissions will be translated into English, after the review process. There are two reasons for this major change. Firstly, the direct publication of original research will allow readers to learn about developments in Chinese educational theory and practice in a timely way. Secondly, we wish to involve a wider range of contributors and demonstrate the open-mindedness of Chinese education research, originating as it does, not only from China, but also from other parts of the world. For a fuller and more multi-dimensional understanding of Chinese education, the journal will combine Chinese points of view with international perspectives, creating a platform for a deepening understanding of Chinese education. We sincerely hope that Frontiers of Education in China can stimulate mutual investigation and multi-dimensional dialogue, such that readers in China and around the world can explore the full meaning of China's educational traditions and contemporary patterns in a global context, thereby genuinely enriching the theory and practice of education. 